\title{
Perturbation of convection-permitting NWP forecasts for flash-flood ensemble forecasting
}

\author{
B. Vincendon, V. Ducrocq, O. Nuissier, and B. Vié \\ Groupe d'étude de l'atmosphère météorologique, URA1357, GAME/CNRM-Meteo France Ctre Nat. Rech. Météo, \\ Météo France, 42 Av Gaspard Coriolis, 31057 Toulouse Cedex 1, France
}

Received: 17 November 2010 - Revised: 28 March 2011 - Accepted: 19 April 2011 - Published: 23 May 2011

\begin{abstract}
Mediterranean intense weather events often lead to devastating flash-floods. Extending the forecasting lead times further than the watershed response times, implies the use of numerical weather prediction (NWP) to drive hydrological models. However, the nature of the precipitating events and the temporal and spatial scales of the watershed response make them difficult to forecast, even using a high-resolution convection-permitting NWP deterministic forecasting. This study proposes a new method to sample the uncertainties of high-resolution NWP precipitation forecasts in order to quantify the predictability of the streamflow forecasts. We have developed a perturbation method based on convection-permitting NWP-model error statistics. It produces short-term precipitation ensemble forecasts from single-value meteorological forecasts. These rainfall ensemble forecasts are then fed into a hydrological model dedicated to flash-flood forecasting to produce ensemble streamflow forecasts. The verification on two flash-flood events shows that this forecasting ensemble performs better than the deterministic forecast. The performance of the precipitation perturbation method has also been found to be broadly as good as that obtained using a state-of-the-art research convectionpermitting NWP ensemble, while requiring less computing time.
\end{abstract}

\section{Introduction}

Flash-floods (FF) are the most costly hazards in the northwestern Mediterranean (Llasat, 2009). They are triggered by heavy rainfall events which often occur in autumn all along the northwestern coast. The geomorphologic characteristics of the region, with steep slopes and small- to medium-size catchments lead to short hydrological response times. Hy-

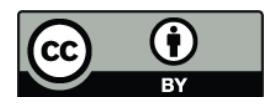

Correspondence to: B. Vincendon (beatrice.vincendon@meteo.fr) drological forecasting systems driven only by rainfall observations do not give forecasts providing sufficient advance warning to prepare for a flash-flood event. Extending the forecasting lead times further than the watershed response times implies the use of quantitative precipitation forecasts (QPF) from numerical weather prediction (NWP) models (Melone et al., 2005; Ferraris et al., 2002).

One critical issue for the use of QPF from NWP models to drive hydrological models is the matter of scales. The temporal and spatial scales of NWP errors are generally much larger than the scales of the corresponding FF (Roberts et al., 2009). It is thus necessary to pre-process atmospheric weather forecasts before they are used for any hydrological purpose (Hamill et al., 2007). The new-generation convection-permitting atmospheric models, which use a horizontal resolution of $1-4 \mathrm{~km}$, are the only NWP models functioning at the scale of hydrological catchments prone to FF. Their QPF can be used directly to drive rainfallrunoff models. Thus, no additional downscaling procedures, like those used for larger scale NWP systems (e.g. Deidda, 2000; Regimbeau et al., 2007), are needed. Several past studies have assessed the value of convection-permitting meteorological forecasts to drive hydrological models dedicated to Mediterranean flash-floods (Anquetin et al., 2005; Chancibault et al., 2006; Vincendon et al., 2009). These studies found that the precipitation underestimation was significantly less marked for the convection-permitting QPF, but there were still uncertainties on rainfall location, which could be detrimental to good discharge forecasting. Even a 50-km shift error, which is considered quite small from a meteorological forecast perspective, can lead the simulation to completely miss a flash-flood event, since the heaviest predicted rain may fall outside the watershed with such a location error.

These studies also show that a meteorological simulation that improves objective scores in terms of quantitative precipitation forecast does not systematically lead to an improved hydrological simulation. Meteorological

Published by Copernicus Publications on behalf of the European Geosciences Union. 
forecasting uncertainties are propagated into hydrological forecasting systems and combine with other uncertainties associated with the hydrological modelling (Krzysztofowicz, 2002; Diomede et al., 2006; Bowler et al., 2006). The initial soil moisture has been shown to be a major source of hydrological modelling uncertainties (Zehe et al., 2005; Le Lay and Saulnier, 2007). Calibration of the model parameters is another source of uncertainties and many studies have tried to address the associated equifinality issues (Beven and Freer, 2001; Montanari, 2005). It is, however, accepted that the uncertainty of the QPF plays the largest role in the uncertainties of the hydrological model prediction in cases of flash-floods (Le Lay and Saulnier, 2007).

Ensemble prediction systems are recognised to be efficient in exploring and quantifying the different types of uncertainties. Numerous studies have used probabilistic precipitation forecasts obtained from atmospheric ensemble prediction systems to drive hydrological models (Bartholmes and Todini, 2005; Siccardi et al., 2005; Davolio et al., 2008; Thielen et al., 2009 among others). Many of these systems, known as HEPS (Hydrological Ensemble Prediction Systems), which are running in operational or nearly operational mode, are listed by Cloke and Pappenberger (2009).

Actions like COST731 (Propagation of Uncertainty in Advanced Meteo-Hydrological Forecast Systems, COoperation in Science and Technology, Zappa et al., 2010), MAP DPHASE (Mesoscale Alpine Programme Demonstration of Probabilistic Hydrological and Atmospheric Simulation of flood Events in the Alpine region, Rotach et al., 2009) or HEPEX (Hydrological Ensemble Prediction EXperiment, Schaake et al., 2007; Thielen et al., 2008) have also contributed to the development of HEPS. Most of the reported HEPS concern medium-range daily streamflow forecasts for large- to medium-size watersheds (e.g. Thirel et al., 2008; Randrianasolo et al., 2010; Thirel et al., 2010).

For flash-flood short-range forecasting, a first approach relies on downscaling the members of operational large scale ensemble forecasting systems to bridge the scale gap between atmospheric model grid and watershed sizes. Downscaling techniques can be either statistical or dynamical or both (Wilby and Wigley, 1997; Xu, 1999; Xuan et al., 2009; Beaulant et al., 2011). Several works aim at downscaling the Ensemble Prediction System (EPS) forecast (Molteni et al., 1996) of the ECMWF (European Centre for Mediumrange Weather Forecasts). Diomede et al. (2006) performed a $10-\mathrm{km}$ resolution dynamical downscaling of "representative members" selected from a clustering of the ECMWF EPS (COSMO-LEPS, Marsigli et al., 2005). Ferraris et al. (2002) added a multifractal disaggregation of the LEPS members to cope with the smaller Mediterranean watersheds. A drawback of these statistical-dynamical downscaling methods is that their use introduces an additional potential source of error.

Convection-permitting ensemble NWP could avoid the resort to a rainfall disaggregation method for the Mediter- ranean small-to-medium catchments, but it is still in its infancy and is computationally expensive. Multi-model approaches (Jasper et al., 2002; Ludwig et al., 2003; Komma et al., 2007) can avoid the numerical cost issue but it is sometimes difficult to find a good overlapping domain. Other numerically cheap methods produce probabilistic precipitation forecasts from single-value model outputs. For instance, post-processing based on spatio-temporal neighbourhoods (Theis et al., 2005) or geographical shift of forecast rainfall fields (Diomede et al., 2008) have been investigated in the past.

The goal of this paper is to go one step further in perturbating high-resolution model QPF. It proposes an alternative approach to take advantage of the progress made by the new convection-permitting operational deterministic NWP systems, in terms of QPF. This approach allows ensemble precipitation fields to be generated that directly match the time and spatial scales of the observed heavy precipitation events and the associated hydrological responses. First, perturbations are introduced in the deterministic convectionpermitting QPF. They are based on model error statistics for north-western Mediterranean heavy rain events. Then, these ensemble precipitation fields are evaluated by driving a hydrological model specifically set up to simulate flash-floods. The QPF perturbation method is compared to a state-of-theart convection-permitting ensemble NWP. The outline of the paper is as follows: Sect. 2 describes the models and Sect. 3 the QPF perturbation method. Then the results are discussed in Sect. 4 and sensitivity analyses are considered in Sect. 5. The conclusion follows in Sect. 6 .

\section{Meteorological and hydrological forecasting systems}

\subsection{The hydrological model}

The ISBA-TOPMODEL hydrological model (Bouilloud et al., 2010) is used to produce ensemble discharge forecasts for the three main catchments of the French CévennesVivarais region (see Fig. 1): the Gardons river at Boucoiran $\left(1090 \mathrm{~km}^{2}\right)$, the Cèze river at Bagnols-sur-Cèze $\left(1110 \mathrm{~km}^{2}\right)$ and the Ardèche river at Vallon Pont d'Arc $\left(1700 \mathrm{~km}^{2}\right)$. The ISBA-TOPMODEL coupled system was designed and calibrated to simulate flash-floods in this area. It fully couples the land surface model ISBA (Interaction Surface Biosphere Atmosphere, Noilhan and Planton, 1989) and a version of TOPMODEL (Beven and Kirkby, 1979) adapted to the Mediterranean context (Pellarin et al., 2002). This coupling consists of introducing a lateral soil water distribution into ISBA following the TOPMODEL concept. The soil-atmosphere interface is managed by ISBA, especially for evaporation and soil infiltration. Then the ISBA soil moisture fields are modified through TOPMODEL lateral transfers based on topographical information. From the new saturated areas and new soil moisture fields obtained, ISBA 
computes sub-surface runoff and deep drainage, which are routed to the watershed outlets to produce total discharges. ISBA-TOPMODEL calibration (fully described in Bouilloud et al., 2010) is limited to two parameters that manage the vertical transfer of soil water (parameters of saturated hydraulic conductivity profile). Once calibrated, ISBA-TOPMODEL proved to be efficient to simulate French Mediterranean flash-floods using hourly observed rainfall such as radar quantitative precipitation estimates (Vincendon et al., 2010). In the work described here, ISBA-TOPMODEL was run in forecasting mode, i.e. using the meteorological forecast to drive ISBA-TOPMODEL during the rainy events. The simulation was started $48 \mathrm{~h}$ prior the rainy event in order to reach a state of balance in the hydrological model (Bouilloud et al., 2010) before the start of the rainfall. During this initial 48-h period, ISBA-TOPMODEL was driven by the observed meteorological forcing. The initial conditions (soil water and temperature) came from the Météo-France operational hydrometeorological system SAFRAN-ISBA-MODCOU (Habets et al., 2008).

\subsection{The atmospheric prediction system}

\subsubsection{AROME deterministic operational forecasts}

The convection-permitting precipitation forecasts were provided by the Météo-France operational model AROME (Seity et al., 2010). AROME is part of the Météo-France operational suite that consists of several nested NWP models. At the time of the study, the global spectral model ARPEGE (Courtier et al., 1991) had a horizontal resolution of about $15 \mathrm{~km}$ over France and produced forecasts up to 102-h range. ALADIN (Bubnovà et al., 1995; Bernard, 2004), a spectral limited-area model coupled to ARPEGE, was issuing up to 54-h forecasts at $7.5 \mathrm{~km}$ horizontal resolution over Western Europe. Since the late 2008, AROME has been running at a $2.5 \mathrm{~km}$ horizontal resolution over a domain mainly covering France.

AROME is based on the non-hydrostatic version of the adiabatic equations of ALADIN. Its physical parameterisations come from the research model Meso-NH (Lafore et al., 1998). No parameterisation of deep convection is needed thanks to the high resolution and a bulk microphysics scheme (Caniaux et al., 1994) that governs the prognostic equations of six water variables (water vapour, cloud water, rain water, primary ice, graupel and snow). Moreover, AROME has its own data assimilation cycle based on a 3-D-VAR data assimilation scheme. The rapid forward sequential assimilation cycle produces 3-hourly data analyses and 30-h forecasts at 00:00, 06:00, 12:00 and 18:00 UTC. The assimilated observations include those from radio-soundings, screen-level stations, wind profilers, weather radar (Doppler winds), GPS, buoys, ships and aircraft, and satellite data. The lateral boundaries were provided by ALADIN forecasts.

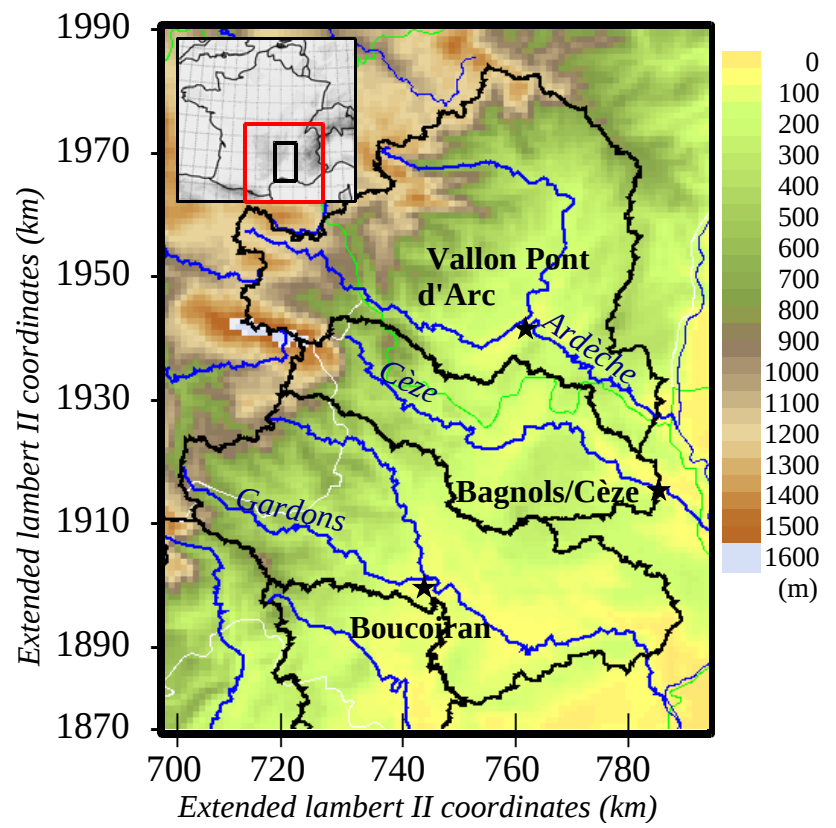

Fig. 1. Location of the main watersheds (delineated in black) and main rivers (in blue) of the Cévennes-Vivarais region. The studied outlets are indicated by stars: Vallon Pont d'Arc for the Ardèche river $\left(1930 \mathrm{~km}^{2}\right)$, Bagnols for the Cèze river $\left(1110 \mathrm{~km}^{2}\right)$, and Boucoiran for the Gardons river $\left(1910 \mathrm{~km}^{2}\right)$. The location of this domain with respect to France is given in the top left corner (black box). The red square delineates the domain $\mathcal{D}$ used for the SAL comparison described in Sect. 3.1.

\subsubsection{AROME ensemble forecasts}

Vié et al. (2010) have developed a convection-permitting meteorological ensemble based on a dynamic downscaling of the ARPEGE ensemble forecasts, called PEARP, (Nicolau, 2002) using the AROME model. The eleven PEARP members are first dynamically downscaled by ALADIN, which provides the lateral boundary conditions to AROME. A mesoscale data assimilation is performed with AROME to improve the mesoscale initial conditions as in the AROME deterministic operational forecasting system. The initial states of the AROME ensemble forecasts (hereafter called AROME-PEARP) are thus relaxed towards the same mesoscale observation sets, although the first-guesses arising from the PEARP members are different. AROMEPEARP mainly samples uncertainties inherent in larger scale lateral boundary conditions. Others ensembles sampling the mesoscale initial condition uncertainties are evaluated in Vié et al. (2010) but are not used here. Vié et al. (2010) computed probabilistic scores to evaluate their ensembles over a 31-day period during the autumn of 2008. Some of the scores showed that, regarding QPF, the probabilistic information outperformed the deterministic forecast. The AROME-PEARP showed a good ability to discriminate the kind of precipitation events, especially high precipitation 
ones, which are interesting within the framework of Mediterranean floods. The AROME-PEARP ensemble was still found to be underdispersive and its reliability, although satisfactory, could also be improved. An important drawback of this method is the high computational cost. Running such a system in real time is hardly affordable with the current computer power dedicated to operational numerical weather prediction. We selected this ensemble as a reference for evaluating our QPF perturbation method.

\section{The QPF perturbation method}

\subsection{AROME deterministic operational QPF uncertainties}

The basic idea was to fully take advantage of the valuable information contained in the AROME deterministic operational forecast to build a set of possible QPF scenarios. A preliminary step was thus to evaluate the errors in location and amplitude of the AROME deterministic operational QPF during heavy precipitation over southeastern France. This allowed us to establish the probability density function (pdf) of the errors that was to be used to generate the QPF ensemble members.

The object-based quality measure SAL defined by Wernli et al. (2008) was selected to verify the hourly AROME QPF. This method can evaluate three different aspects of the quality of rainfall forecast fields over a specific domain: their structure $(S)$, their location $(L)$ and their amplitude $(A)$. Their formulation is given in Appendix A. This method is suitable for the verification of QPF from convectionpermitting weather prediction models on short time scales. It is also well-fitted to the object-based QPF perturbation method described in this paper.

The SAL method was applied to verify the hourly AROME QPF against the quantitative precipitation estimates (QPE) from radar data over the domain $\mathcal{D}$ shown in Fig. 1. The domain encloses the three watersheds but is a little larger than the area covered by them in order to better cope with the size of the mesoscale precipitation systems inducing heavy precipitation in that region. The $1 \mathrm{~km}^{2}$ resolution radar QPE is based on the Météo-France weather radar network and calibrated by raingauges (Tabary, 2007, Tabary at al., 2007). The verification sample contained all the significant rainy events (24 days) that occurred over the domain from October 2008 to October 2009. A rainy event was considered as significant if the daily rainfall exceeded $70 \mathrm{~mm}$ at least at one raingauge station of the domain. The SAL method was applied to each hourly QPF in the $3 \mathrm{~h}$ to $24 \mathrm{~h}$ forecast range, as the two first hours of forecasting might have been damaged due to AROME spin-up. For each day of the sample, the four daily AROME operational simulations based on the analyses of 00:00, 06:00, 12:00 and 18:00 UTC, were available. Thus, the evaluation sample included more than 1100 hourly QPF fields in total. The hourly QPF were not all independent, but this large number of fields permited us to assume that the comparison would not be biased.

The SAL method first requires individual precipitation objects to be identified in both the observed and forecasted hourly rainfall fields. The precipitation objects are defined as continuous grid points exceeding a fixed threshold. Two different thresholds are used to enclose coherent objects in the threshold contour. A first threshold is fixed at a low value $\left(2 \mathrm{~mm} \mathrm{~h}^{-1}\right)$ to delineate the rainy areas (hereafter called "rainy objects"). Then a second higher value $\left(9 \mathrm{~mm} \mathrm{~h}^{-1}\right)$ enables the areas with convective rainfall (called hereafter "convective objects") to be identified within the rainy objects. This threshold has been found to be the most suitable for capturing the convective signature of the precipitating systems such as the convective line within the mesoscale convective systems observed over the region.

Figures 2 and 3 show SAL diagrams for the rainy and convective objects respectively. These SAL diagrams as proposed by Wernli et al. (2008) synthesise the SAL components on a single graph. The abscissa and ordinate correspond to the $S$ and $A$ component, respectively, and the colour of the point is for the $L$ component. The scale of colour is indicated in the layout. The clear dots situated in the centre of the diagram represent very good forecasts. Positive [negative] values of $A$ indicate an overestimation [underestimation]. Concerning the $S$ component, negative values occur for too small objects and/or for objects with too high an inner gradient (also referred to by Wernli et al. (2008) as "too peaked objects"). Conversely, positive values of $S$ occur for too large objects or objects with too low an inner gradient (also referred as "too flat objects") or a combination of both. Dashed lines indicate the median values of $S$ and $A$. The white square has the 25th percentile of the distribution of $S$ as abscissa and the 25th percentile of the distribution of $A$ as ordinate. Similarly, the black square corresponds to 75 th percentiles of $S$ and $A$. For both the $2 \mathrm{~mm}$ and $9 \mathrm{~mm}$ thresholds, the median of the $A$ component is very close to zero, indicating that there is no systematic underestimation (or overestimation) of the intensity of the rainfall. Figures 2 and 3 show that most of the AROME forecasts are quite satisfactory, since they lead to absolute values of A and $S$ smaller than 1.5. Indeed, A and $S$ components are constructed to vary between -2 and +2 , with 0 corresponding to a perfect forecast. Values of $L$ smaller than 1 show that location errors are small, since the $L$ component is never in the range [1,2]. Moreover, the points are situated along the main diagonal of the diagram for the $2 \mathrm{~mm}$ threshold (Fig. 2), which shows that the behaviour of the model is consistent. The model overestimations of precipitation amounts go with too-large and/or too-flat objects. In contrast, the model tends to underestimate rainfall amounts because of too-small and/or too-peaked objects. The cases of underestimation are slightly more frequent than the opposite cases since the medians of $A$ and $S$ are both negative. 

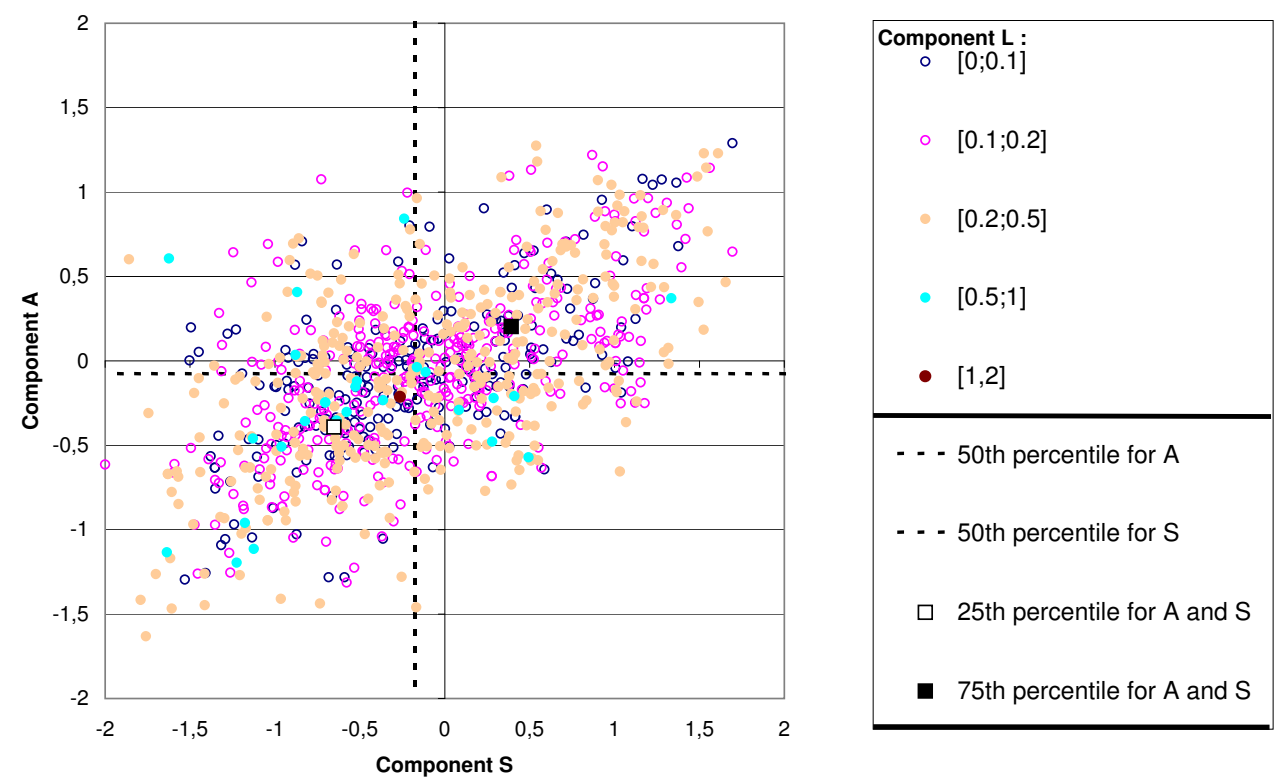

Fig. 2. SAL diagrams for the hourly precipitation forecast of AROME for the threshold $2 \mathrm{~mm} \mathrm{~h}^{-1}$. Every dot shows the value of the three components of SAL for a particular hour of the days of the sample. The $L$ component is indicated by the colour of the dots (see scale on the top of the layout). Median values of $S$ and $A$ are shown as dashed lines, the squares correspond to the 25th (white) and 75th (black) percentiles of the distributions of $S$ and $A$. (see Appendix A for more details).
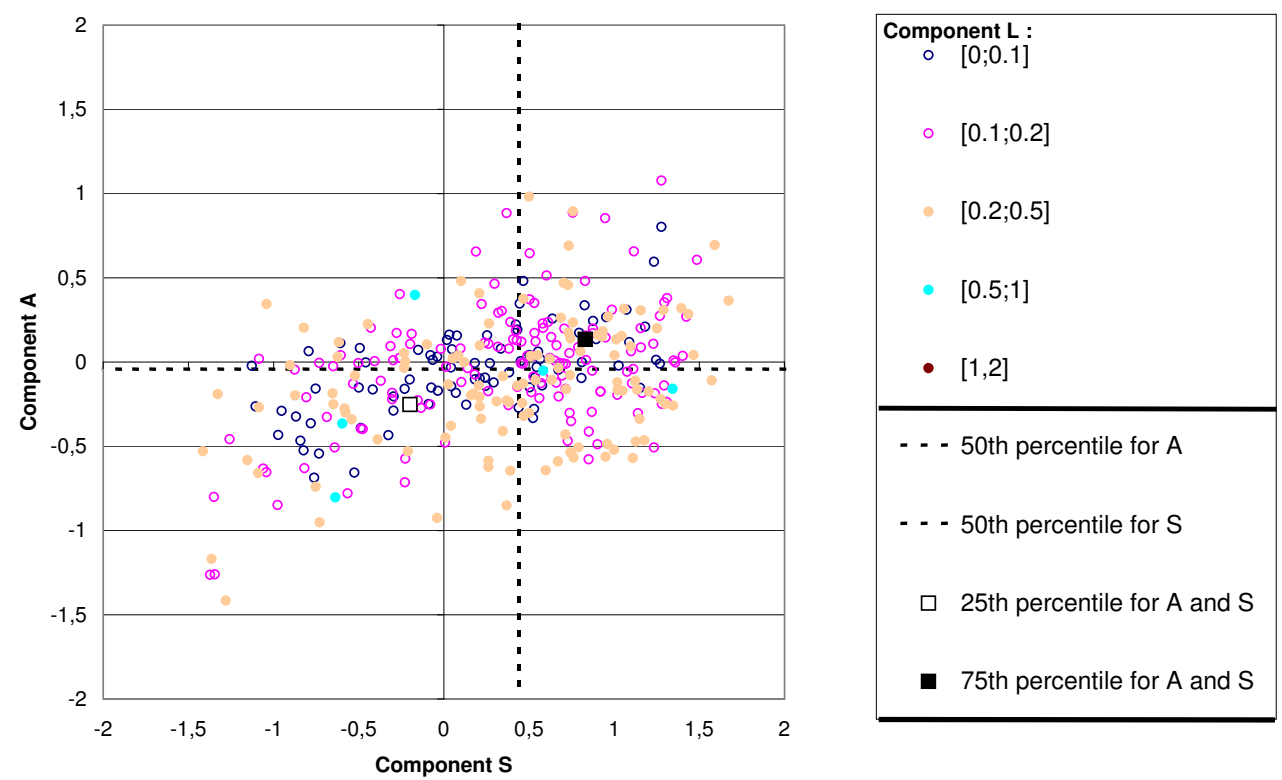

Fig. 3. Same as Fig. 2, but for the threshold $9 \mathrm{~mm} \mathrm{~h}^{-1}$.

For the convective objects (Fig. 3), the $S$ component is more frequently positive. Consequently, the simulated objects are too-large and/or too-flat even when rainfall amounts are underestimated (i.e. in the bottom right quadrant). This occurs when the model predicts stratiform precipitation in a situation with intense localised showers.
The L component does not show systematic behaviour with $S$ and $A$ components. Dots of any colour can be found in the four quadrants.

In addition, we estimated the probability density function (pdf) of the location and amplitude errors on the same objects as those used for the SAL diagnoses (Figs. 4 and 5). Concerning the location error, we computed the geographical 
(a) Shift along $X$ axes

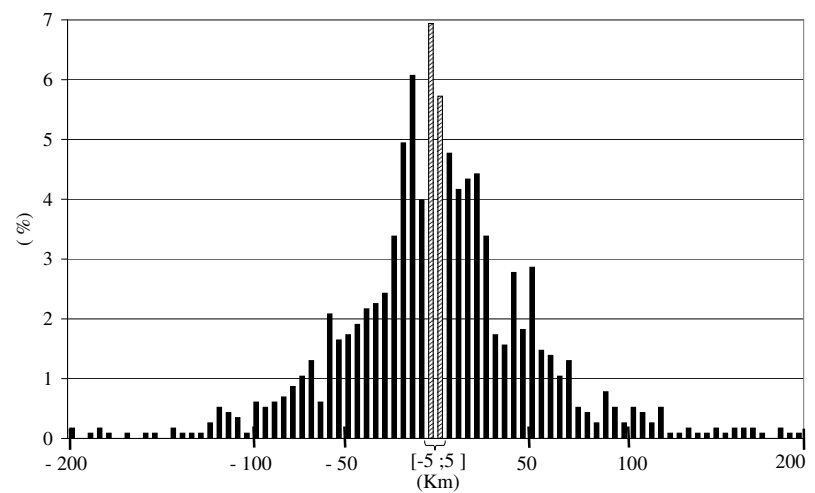

(b) Shift along $\mathrm{Y}$ axes

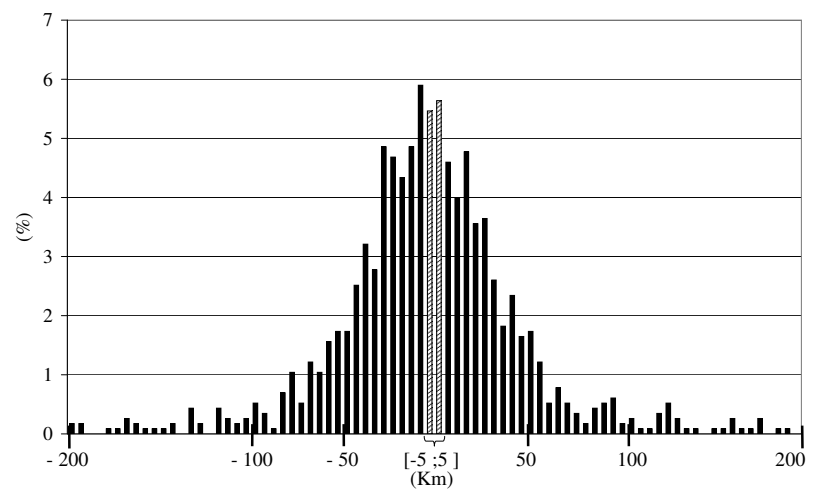

Fig. 4. Empirical pdf for location errors (km) along $X$ (a) and $Y$ (b) axes.

shift along the west-east $(X)$ and north-south $(Y)$ directions for each object. The values of the location errors are shown in Fig. 4a, b. The distance between the barycentre of simulated and observed objects shows that in about 80 percent of the cases, the shift (in the either direction) does not exceed $50 \mathrm{~km}$. The amplitude error is computed as the ratio between mean surface precipitation within simulated and observed objects. This factor is called $f$ for rainy objects and $f_{c}$ for convective ones (Fig. 5a, b). The distribution of $f_{c}$ is well-centred around the value 1 , whereas for $f$ the major class is for a value between 0.8 and 0.9. Similar results were obtained whatever the range of the AROME forecast (not shown). This object-based approach shows that the deterministic QPF on which the QPF perturbation ensemble will be built is not subject to systematic errors and provides a valuable possible scenario that is not too far from the observed one.

\subsection{Perturbation generation}

The method for generating an ensemble of rainfall forecasts is also based on an object-oriented approach taking advantage of the SAL evaluation. The perturbation method is based on the following principles: (a) Rainy objects mean amplitude error

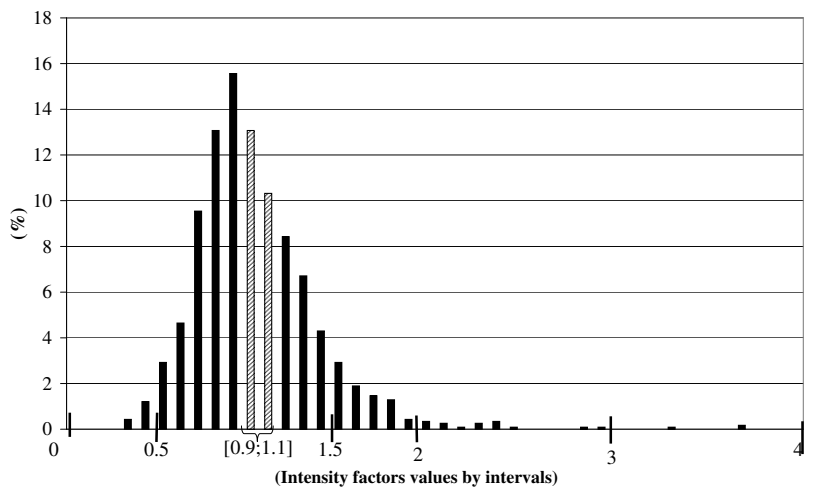

(b) Convective objects mean amplitude error

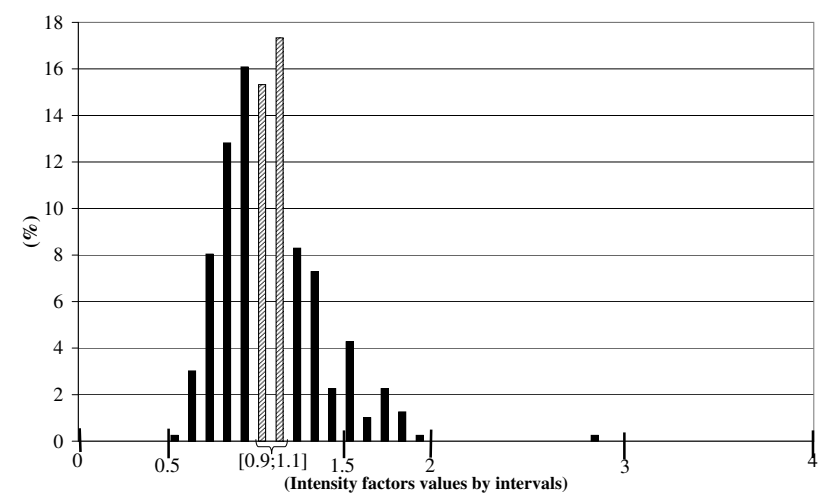

Fig. 5. Empirical pdf for amplitude error for rainy objects (a), coefficient $f$ and convective objects (b), coefficient $f_{c}$. Values are represented sorted by classes.

- The rainy objects are moved according to the pdf of the location errors of the AROME deterministic forecast.

- The intensity of the rain inside the rainy objects is modified according to the pdf of the amplitude errors of the AROME deterministic forecast.

- The convective objects within each rainy object are set more or less peaked/flat according to the pdf of the amplitude errors of the convective objects.

Figure 6 represents the steps of this perturbation method. First, rainy objects are selected within the AROME deterministic hourly rainfall field at time $t_{0}$ over the domain $\mathcal{D}$. These rainy objects are moved by steps of $5 \mathrm{~km}$ along the $\mathrm{x}$ and $\mathrm{y}$-axes of the conformal projection plane. This geographical shift is limited to $|X Y|$ kilometres. Among all the possibilities, $N(x, y)$ pairs are randomly selected according to the pdfs of the location errors of the AROME deterministic forecast, which are assumed to be independent (see Sect. 3.1) to produce $N$ rainfall members. Then, for each member $n$, the rainfall intensity at each pixel of the rainy object, that is not included in a convective object, is multiplied 


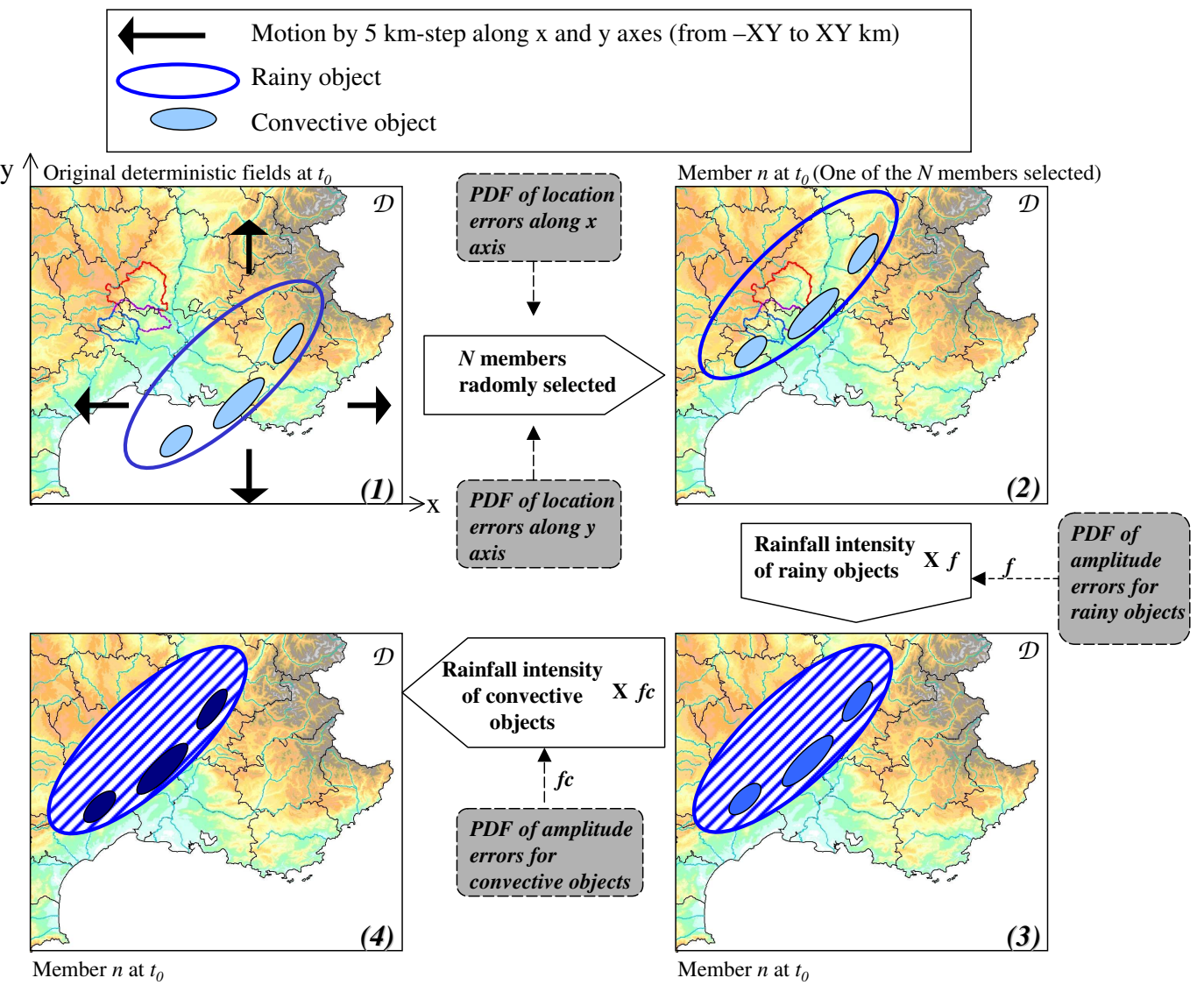

Fig. 6. Principle of the perturbation generation method at time $t_{0}$.

by a factor $f$, randomly selected according to the pdf of the amplitude errors of the AROME deterministic forecast. Finally, the rainfall intensity of each pixel of the convective objects within the rainy objects is multiplied by a factor $f_{c}$, randomly selected according to the pdf of the amplitude errors of the convective objects. The same displacement $(x, y)$ and intensity factors $f$ and $f_{c}$ apply from forecasting range $t_{0}$ to the final range $t_{f}$, to define a physically consistent rainfall scenario for each member. This method is called PERTRAIN hereafter.

So PERT-RAIN has been designed to take advantage not only of the capabilities of the convection-permitting NWP models to produce rain fields of better quality that are more relevant to the hydrological scales involved in flash-flood forecasting, but also of the climatology of the AROME model errors, in terms of both amplitude and location. With this method, the spatial distribution of precipitation within the rainy object is not governed by statistical laws. It follows the physical distribution given by the convection-permitting model that takes the synoptic meteorological situation, the orography and the meso-scale processes involved into account. Within Mediterranean heavy precipitation systems, the convective cells are not randomly distributed but generally organised along the leading edge facing the marine low-level flow (Ducrocq et al., 2008). Our method retains this physical property.

PERT-RAIN is applied to each hourly AROME QPF from $3 \mathrm{~h}\left(t_{0}\right)$ to $24 \mathrm{~h}\left(t_{f}\right)$ of the forecast. The reference simulation PERT-RAIN considers $50(N)$ members, which can be displaced up to $\pm 50 \mathrm{~km}$ (XY) along the $\mathrm{x}$ and $\mathrm{y}$-axes, and have intensity factors $f$ and $f_{c}$ that can vary from 0.5 up to 1.5. Values of $N$ and $X Y$ are chosen considering the sensitivity analyses described in Sect. 5. The 50 rainfall scenarios are used to drive ISBA-TOPMODEL. The other parameters necessary to drive ISBA-TOPMODEL still come from the AROME deterministic operational forecast.

\section{Ensemble streamflow forecast evaluation}

\subsection{Flash-flood cases}

Hydrometeorological ensemble forecasts were performed for the two flash-flood events included in the AROME-PEARP evaluation period of Vié et al. (2010): 21-22 October 2008 and 1-2 November 2008.

Southeastern France was concerned by an upper-level trough, which was not very pronounced by 21 October. A 
Oct. case :

(a)

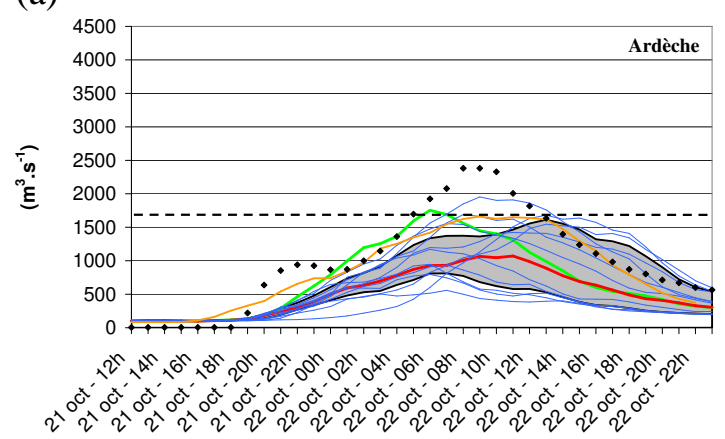

(c)

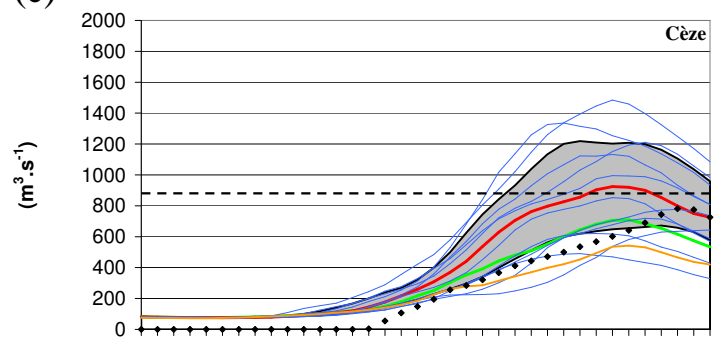

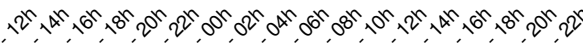

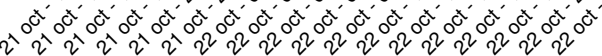

(e)

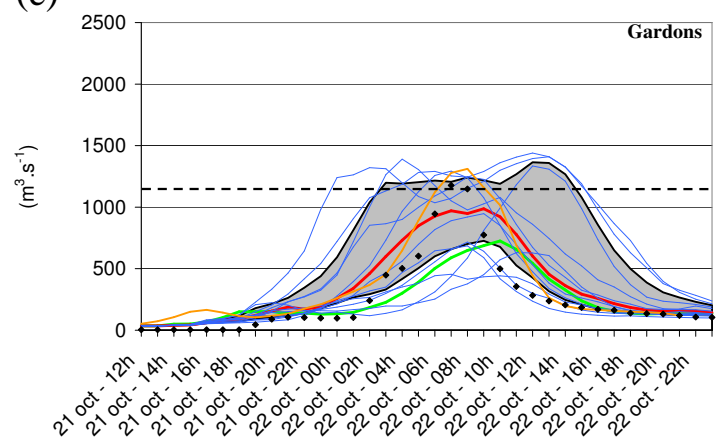

Nov. case :

(b)

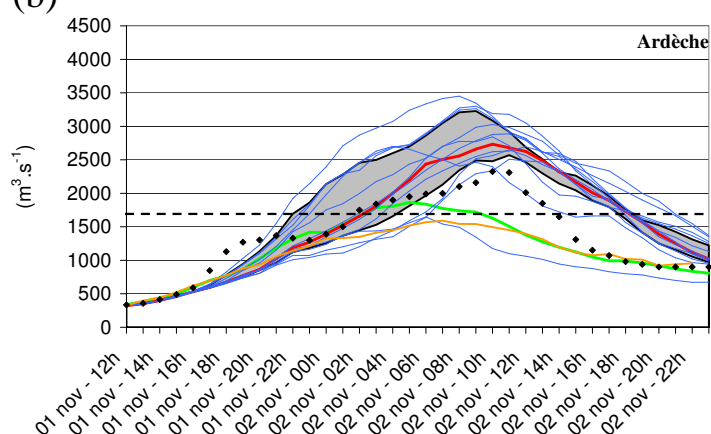

(d)

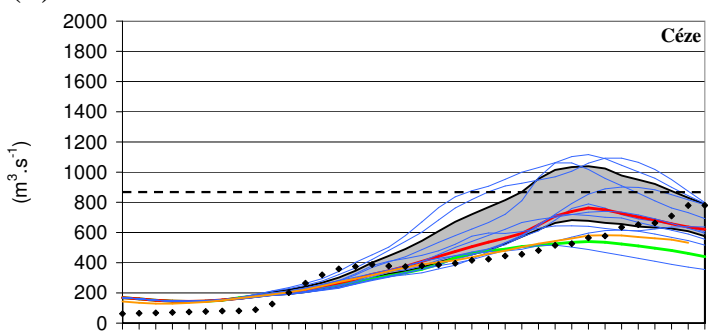

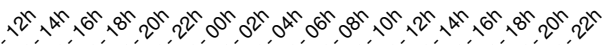

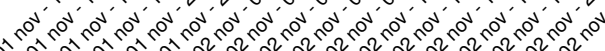

(f)

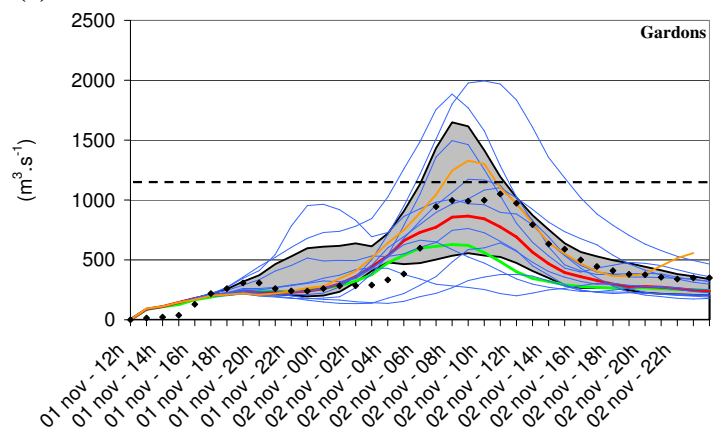

Fig. 7. Observed and forecast discharge time-series from 21 October 2008 at 12:00 UTC to 23 October 2008 at 00:00 UTC (left) and from 1 November 2008 at 12:00 UTC to 3 November 2008 at 00:00 UTC (right) over the three Cévennes-Vivarais watersheds: Ardèche at Vallon Pont d'Arc (a, b); Cèze at Bagnols (c, d); Gardons at Boucoiran (e, f). Hourly observed discharge is plotted as black diamonds, forecast discharge with ISBA-TOPMODEL using the members of AROME-PEARP ensemble simulation as blue curves. The red curve is for the ensemble median. The shaded area represents the interquartile range. The green curve is the forecast discharge with ISBA-TOPMODEL using the AROME deterministic operational forecast. The orange curve is the simulated discharge with ISBA-TOPMODEL using the radar quantitative precipitation estimation. The dashed black line is the warning reference level used by the French operational flood forecasting centre.

frontal disturbance moving eastward was strengthened by the south to south-easterly convergent low-level flow that supplied moisture from the Mediterranean. The largest rainfall occurred over the foothills of the Cévennes on the evening of 21 October. Daily rainfall reached $470 \mathrm{~mm}$ at Le-Grand-Combe raingauge in the Gard department. This led to a significant rise of the water level of Gardons, Cèze and Ardèche rivers. The AROME deterministic operational forecast based on the 21 October at 12:00 UTC analysis produced high rainfall amounts over the Cévennes catchments. The rainy object location in the AROME forecast approximately matched the observed precipitation area but the convective part was underestimated in terms of both spatial extent and maximum rain intensity.

Another heavy precipitation event affected the Cévennes area ten days later. A strong upper-level trough approached 
Table 1. Mean areal rainfall (mm) on 2 November 2008 from 00:00 UTC to 24:00 UTC over Gardons (at Boucoiran), Cèze (at Bagnols) and Ardèche (at Vallon Pont d'Arc) from radar QPE and from AROME operational forecast based on the 2 November 2008 at 00:00 UTC analysis.

\begin{tabular}{llll}
\hline Catchment & $\begin{array}{l}\text { Boucoiran } \\
\text { (Gardons river) }\end{array}$ & $\begin{array}{l}\text { Bagnols/Cèze } \\
\text { (Cèze river) }\end{array}$ & $\begin{array}{l}\text { Vallon } \\
\text { (Ardèche river) }\end{array}$ \\
\hline AROME & 113.7 & 94.8 & 255.6 \\
RADAR & 101.9 & 60.2 & 120.9 \\
\hline
\end{tabular}

France from 31 October and evolved into a cut-off low over the Iberian peninsula by 2 November. A surface low pressure centre was located over southwestern France, which generated a rapid northward advection of moist, warm marine air. The Cévennes area was affected by heavy rain and river flooding. From 1 November 12:00 UTC to 2 November 12:00 UTC, around $400 \mathrm{~mm}$ were recorded locally over the Massif Central foothills. The AROME operational forecasts underestimated the maximum rainfall totals. $24 \mathrm{~h}$-accumulated precipitation reached no more than $200 \mathrm{~mm}$. The rainy objects in the AROME forecasts were also located too far north compared to the observed ones. But the areal rainfall forecast (mean value on Gardons, Cèze and Ardèche catchments) from the AROME deterministic operational forecast based on the 2 November 00:00 UTC analysis had values close to the observations or higher (see Table 1).

\subsection{AROME-PEARP streamflow forecasts}

A first set of streamflow ensemble forecasts was produced by the ISBA-TOPMODEL hydrological system driven by the eleven AROME-PEARP ensemble rainfall forecasts described in Sect. 2.2.2. This set constitutes our reference for evaluating the performance of the PERT-RAIN method in the following sections and for the sensitivity analyses. Figure 7 shows the discharges simulated by ISBA-TOPMODEL using AROME-PEARP hourly rainfall ensemble members for the October and November cases. The discharge simulation starts at 12:00 UTC (either on 21 October or on 1 November) and uses hourly QPF up to $24 \mathrm{~h}$. The simulations are extended up to $36 \mathrm{~h}$-range using zero rainfall intensity for the last $12 \mathrm{~h}$ to include the observed flood peak for the three catchments. The green and orange curves are for the discharges simulated by ISBA-TOPMODEL driven by the AROME deterministic forecast and the radar QPE, respectively. The shaded area in Fig. 7 represents the ensemble spread between quantiles $q_{0.25}$ and $q_{0.75}$ of the members. The dashed black line represents the warning level used in the national operational flood forecasting centre.
For both cases, the median of the members is generally closer to the observations or to the radar-driven simulation than the simulation driven by the AROME deterministic operational forecast. The radar-driven simulation helps to estimate the uncertainties associated with the hydrological modelling although some of the uncertainties come from the radar observations themselves. For all cases, both the median and the ensemble spread simulate a significant flood peak. This shows that this probabilistic approach introduces useful information compared to the deterministic approach in both cases. Considering streamflow ensembles with respect to the warning level gives an idea of the risk of exceeding this level and so of being faced with a potentially dangerous situation. However, the quality of the results depends on the catchment and the case. Most of the time, the observed flood peak is included into the ensemble spread except for the Ardèche watershed. For this watershed, the flood peak is underestimated by all the members for the October case and overestimated by most of the members for the Nov. case. Simulated discharges are of course strongly linked to the total precipitation falling over the watershed. For instance, the flow peak underestimation by all the members for the October case is well explained by rainfall totals smaller than the radar rainfall estimate (Fig. 8).

\subsection{Perturbed rainfall forecasts}

The discharge time-series simulated by ISBA-TOPMODEL driven by the PERT-RAIN scenario are shown in Fig. 9. Many of the members lead to an underestimation of the discharge with no flood at all. Also some members strongly overestimate the peak flow. Nevertheless, the median and the interquartile range provide information about a flood occurrence. The median is either closer to observations than the deterministic forecast or, at least, it informs on the risk of a flood which was already identified by the deterministic forecast. The stream flow ensemble is also informative as far as flow peak timing is concerned. Of course, encouraging as these results on two events may be, they need to be confirmed on more cases.

The PERT-RAIN interquartile range (shaded area in Fig. 9) is of the same order as our reference (AROME-PEARP). Overall, the PERT-RAIN median discharges are smaller than the AROME-PEARP ones, except for the November case over the Gardons watershed and for the October case for the Ardèche watershed. The PERT-RAIN median flow peaks are generally closer to the observed ones or of the same accuracy as the AROME-PEARP median peaks, except for the October case over the Gardons watershed. It is worth mentioning that even if the perturbation only concerns rainfall location and amplitude (not the rainfall time evolution), we obtained quite different precipitation time-evolution patterns over the watersheds with PERT-RAIN.

A more objective comparison was made between the PERTRAIN method and the AROME-PEARP ensemble (Table 2). 
Table 2. Hourly discharges $\left(m^{3} . s^{-1}\right)$ RPSS, RMSE and $\sigma$ of the ensembles AROME-PEARP and PERT-RAIN (10 members) at Boucoiran, Bagnols and Vallon Pont d'Arc. The values are written in bold when they are better than those of the competing experiment.

\begin{tabular}{|c|c|c|c|c|c|c|}
\hline Catchment & Boucoiran(Gardons river) & & Bagnols/Cèze (Cèze river) & & Vallon (Ardèche river) & \\
\hline Ensemble & AROME-PEARP & PERT-RAIN & AROME-PEARP & PERT-RAIN & AROME-PEARP & PERT-RAIN \\
\hline RPSS & 0.30 & 0.19 & 0.06 & -0.18 & -0.06 & -0.04 \\
\hline RMSE & 185.8 & 173.3 & 158.1 & 104.6 & 504.7 & 462.1 \\
\hline$\sigma$ & 221.1 & 158.0 & 116.4 & 136.9 & 290.5 & 221.1 \\
\hline
\end{tabular}

Table 3. Sensitivity experiments concerning the modification method.

\begin{tabular}{llll}
\hline Experiment name & Modification applied & $N$ values & $X Y$ values \\
\hline PERT-A & Rainfall intensity only $(f)$ & 10 & None \\
PERT-S & Structure only $\left(f_{c}\right)$ & 10 & None \\
PERT-L & $\begin{array}{l}\text { Only location of } \\
\text { rainy objects } \\
\text { modified }\end{array}$ & 10 & $25 \mathrm{~km} / 50 \mathrm{~km}$ \\
& All modifications of the & & \\
PERT-R $[N]$ & PERT-RAIN (=PERT-R50) method & $40,50,30$ & $50 \mathrm{~km}$ \\
& & \\
\hline
\end{tabular}

The same number of members are considered for both the PERT-RAIN and AROME-PEARP methods to permit a fair comparison (Richardson, 2001). Only ten members were considered in PERT-RAIN so as to fit the AROME-PEARP ensemble size. In order to compare both streamflow ensembles in terms of mean error and spread, the Root Mean Square Error of the ensemble (RMSE) and the ensemble spread $(\sigma)$ was computed for the hourly discharges at the three outlets. The reference was given by observed hourly discharges. An informative ensemble will lead to weak values of RMSE and to an order of magnitude of $\sigma$ not higher than the RMSE one. Then, to evaluate the improvement with respect to the deterministic AROME forecast, the Ranked Probability Skill Score (RPSS) score was computed for the three catchments. RPSS gives an idea of the performance of an ensemble compared to a reference forecast (here the deterministic model). The values obtained are quite close for both methods. These scores confirm the visual inspection of the hydrograph: there is no method that systematically performs better than the other. For instance, PERT-RAIN obtains better scores than AROME-PEARP for the Ardèche watershed whereas the opposite is true for the Cèze river.

\section{Sensitivity analyses}

Some additional experiments were carried out to examine the sensitivity of the PERT-RAIN method to its degrees of freedom. The characteristics of the sensitivity experiments are given in Table 3 . The sensitivity experiments were evaluated on the same October and November 2008 cases for
Quantitative Discharge Forecasts (QDF) but also on a larger sample of heavy precipitation events for QPF. As AROME forecasts have only been available since 2008, a compromise was made between building an independent evaluation sample and a sufficient sample size. The QPF sample was thus composed of both the October and November 2008 events and five events with rainfall exceeding $70 \mathrm{~mm}$ day $^{-1}$ in 2009 and 2010. The four events in 2010 were outside the period used to establish the AROME error climatology on which the PERT-RAIN method is based. Scores were computed for 24hour accumulated rainfall. The QDF was not evaluated on this period to save computer time and, also, discharge observations have not yet been quality checked for this recent period.

Figure 10 shows the RPSS score computed on the 24-h rainfall totals of the whole evaluation sample for all the sensitivity experiments. Experiments PERT-R $N$ with the number of members $N$ varying from 50 to 10 (Table 3) allows an examination of how much the PERT-RAIN method deteriorated with fewer members. As expected, decreasing the number of members deteriorates the RPSS score. The impact is larger when going from 10 to 20 members than when further enlarging the ensemble size. Similar conclusions were drawn from QDF. The simulated hydrograms for experiments PERT-R10 to PERT-R50 for the Nov. case or October case (not shown) led to a median of the ensemble that fitted the observations better when the number of members was increased.

Then, in order to evaluate the impact of the different steps of the perturbation method, a series of three experiments was defined by perturbing the structure, amplitude and location characteristics of the simulated objects separately. In the 
(a) Oct. case

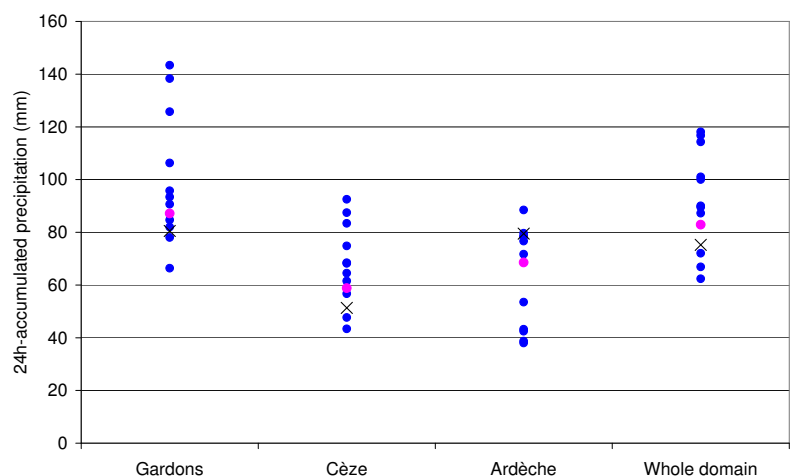

(b) Nov. case

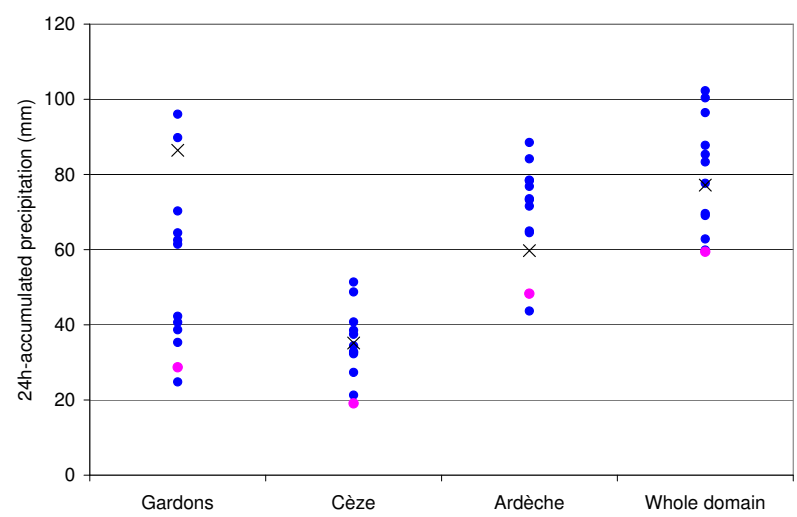

Fig. 8. 24h-accumulated rainfall (in $\mathrm{mm}$ ) averaged over the three watersheds and over the whole domain from radar data (black crosses), the AROME deterministic operational forecast (pink circle) and the members of the AROME-PEARP ensemble (blue points) between 21 October 2008 at 12:00 UTC and 22 October 2008 at 12:00 UTC (a) and between 1 November 2008 at 12:00 UTC and 2 November 2008 at 12:00 UTC (b).

PERT-L experiment, only the location of the rainy objects was modified (step 1 of the perturbation method). In PERT-A only step 2, varying the amplitude of the rainy object through $f$, was kept. For the members of PERT-S, only the amplitude of the convective objects was modified (step 3 of the perturbation method) through $f_{c}$. These experiments were performed with 10 members only in order to reduce the computational cost. When only the location varied (PERT-L), keeping the same $X Y=50 \mathrm{~km}$ maximum range as in the full PERT-RAIN ensemble, the RPSS value was slightly smaller than with the full method (PERT-R10). When the maximum range is reduced to $X Y=25 \mathrm{~km}$, the skill was significantly reduced. The skill became negative which means that the ensemble forecast was less accurate than the reference. When the location of the forecasted objects was not modified in the perturbation method (for PERT-A and PERT-S experiments), the RPSS was further reduced (Fig. 10). Regarding the QDF, Fig. 11 presents the peak discharge error for each member according to $f$ (for experiment PERT-A) or $f_{c}$ (for experi- ment PERT-S) values. Although the $f_{c}$ pdf is almost symmetric, the QDF are underestimated for almost all values of $f_{c}$. Even though the error is reduced with the larger values of $f$, peak discharges remain underestimated most of the time. These results confirm the necessity of considering perturbations both in location and in amplitude. For the cases studied, the location perturbations had a larger impact than the amplitude perturbations. Allowing displacement of the rainy objects up to $50 \mathrm{~km}$ for the perturbations is better for cases with larger errors in location of the AROME deterministic operational forecast. These results are confirmed when the streamflow ensemble obtained for experiments PERT-L, PERT-A, PERT-S and PERT-R is considered. The more satisfactory ensemble, on the basis of the two study cases of November 2008 and October 2008, was obtained for the PERT-R experiment, that is when location, amplitude and structure were perturbed.

\section{Conclusions}

Short-term precipitation ensemble forecasts for Mediterranean flash-floods can be produced from hourly forecasts issued by a convection-permitting meteorological deterministic model. For this, a perturbation method has been developed. The meteorological ensemble forecasts are fed into the ISBA-TOPMODEL model, which was specifically set up to simulate flash-floods to produce ensemble streamflow forecasts. The perturbation method tries to take advantage of the high-resolution, process-based model trajectory of the new generation convection-permitting NWP forecasts. In addition, it also allows the uncertainty to be sampled in both location and magnitude of the precipitation forecast. This method makes use of the location and magnitude errors of the meteorological AROME model QPF in southeastern France.The SAL object-oriented verification method of Wernli et al. (2008) has been found to be well suited to separately evaluating the errors of the rainfall forecasts in terms of location, amplitude and structure. No systematic biases of the AROME QPF have been found. More specifically the general drawback of underestimation of heavy precipitation by the coarser NWP models is not found for the convectionpermitting AROME model. Errors in location do not exceed $50 \mathrm{~km}$ in $80 \%$ of cases. Consequently, one can consider that AROME QPF are of good quality as far as heavy rainfall is concerned. This justifies the approach developed for the PERT-RAIN perturbation method, directly based on the high-resolution model scenario and its simulated rainy objects.

The verification performed on two different cases of flashfloods shows that the precipitation ensembles generated from the PERT-RAIN ensemble method improve the streamflow forecast quality with respect to the deterministic single-value AROME forecast. The quality of the PERT-RAIN ensemble method is generally as good as that obtained using a 
Oct. case :

(a)

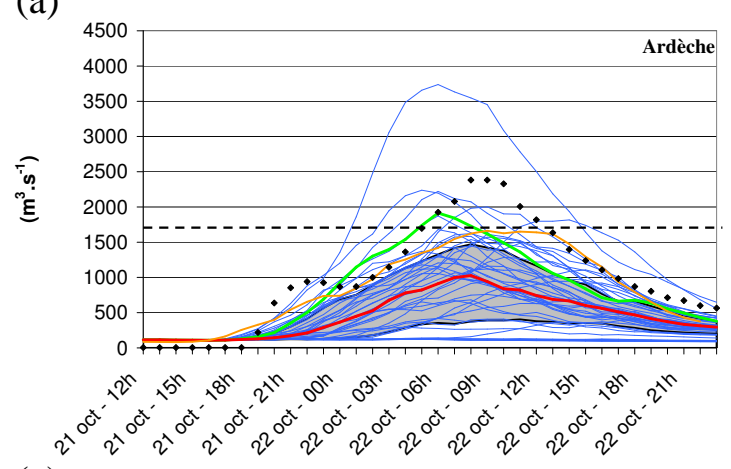

(c)

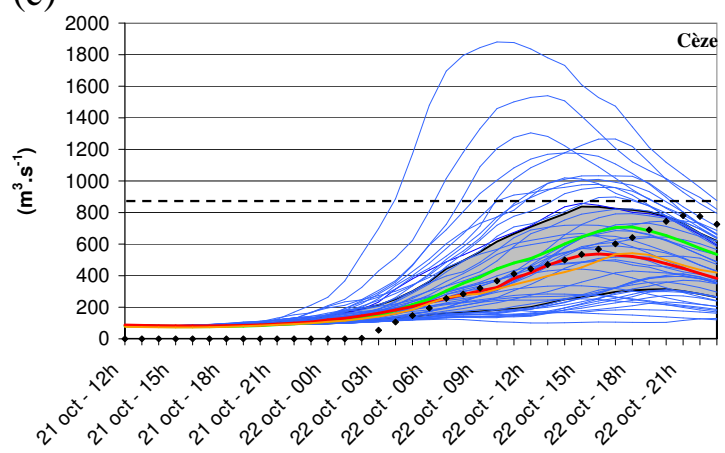

(e)

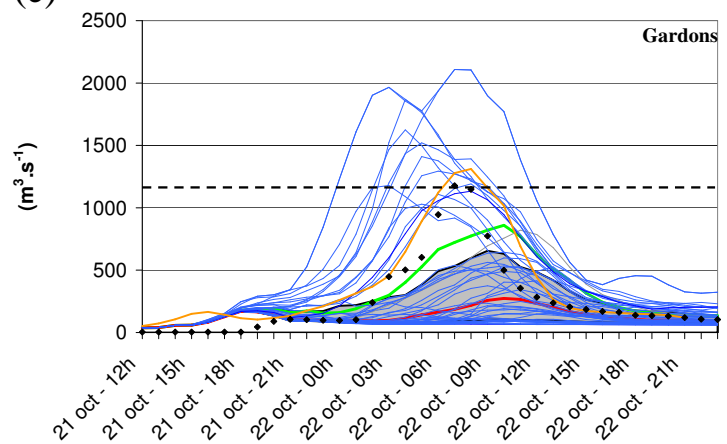

Nov. case :

(b)

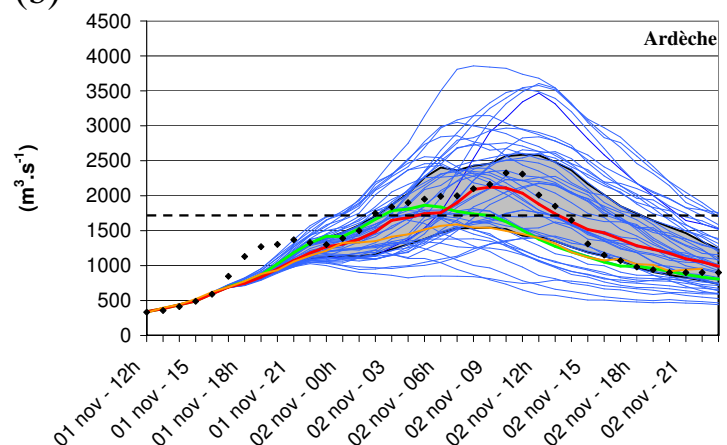

(d)

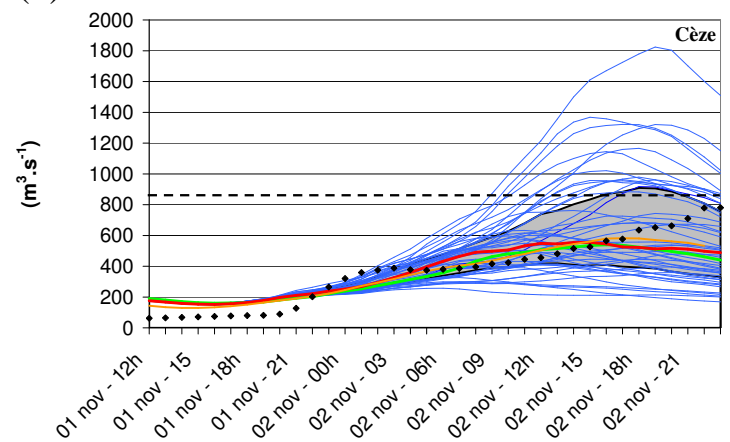

(f)

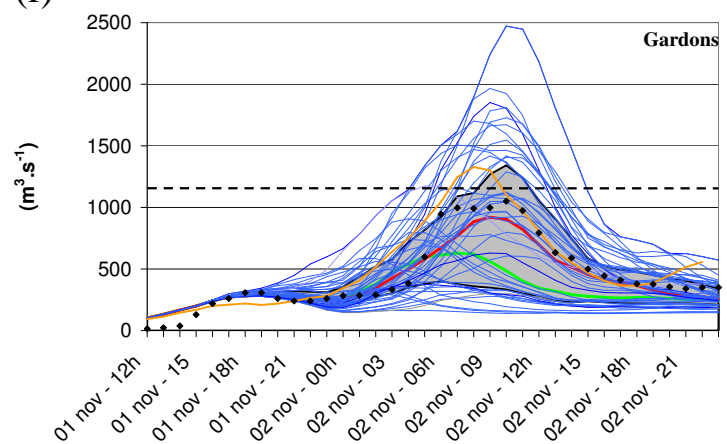

Fig. 9. Same as Fig. 7, but ISBA-TOPMODEL is driven by the members of the PERT-RAIN ensemble.

state-of-the-art research convection-permitting NWP ensemble (AROME-PEARP). The sensitivity analyses show that an ensemble size larger than 20 members provides better skill regarding the deterministic forecast than ensembles with fewer members. The perturbations in location have the strongest impact on the skill of the ensemble. However, the best ensemble, in terms of both precipitation forecast and streamflow simulation, was obtained when the three kinds of perturbation were combined (location, amplitude and structure). Further verification on a larger size sample of flashflood cases is still needed to confirm these promising results. The observing periods of the HYMEX field experiment (http://www.hymex.org) will also provide a test-bed for evaluating the method in a real-time framework.
The PERT-RAIN method is based on the pdf of AROME QPF errors. Completing our climatology of those errors will be a way to improve the skill and reliability of the PERTRAIN ensemble. For instance, it could be useful to determine location error in terms of distance rather than using $\mathrm{x}$ and $\mathrm{y}$ coordinates errors and also to determine different PDFs for each forecast range.

The first advantage of the PERT-RAIN approach is its rather low computer time cost with respect to that of convectionpermitting NWP ensembles. So this method could already be applied to pre-process single-value convectionpermitting operational NWP forecasts for real-time probabilistic streamflow forecasting. Moreover, this method could also be applied to each member of the future convection- 


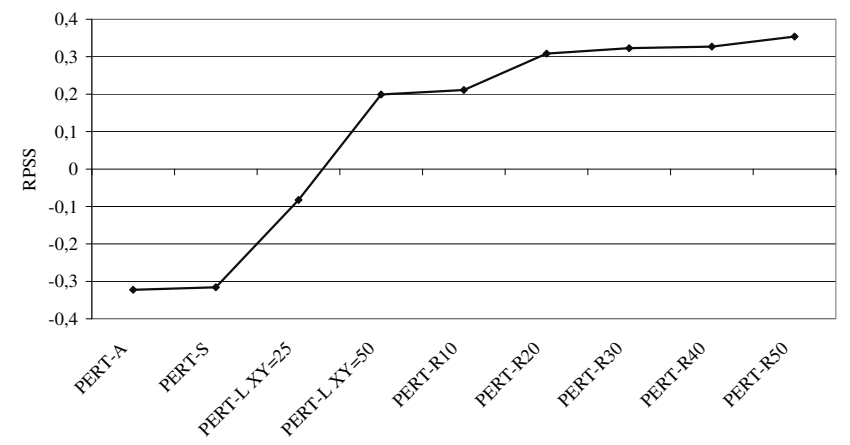

Fig. 10. 24h-accumulated rainfall $\left(\mathrm{mm} \mathrm{day}^{-1}\right)$ RPSS for the ensembles obtained with experiments PERT-A with $N=10$, PERT-S with $N=10$, PERT-L with $N=10$ and $\mathrm{XY}=25 \mathrm{~km}$, PERT-L with $N=10$ and $\mathrm{XY}=50 \mathrm{~km}$, PERT-R $N$ with $\mathrm{XY}=50 \mathrm{~km}$ and varying the number of members $(N)$.

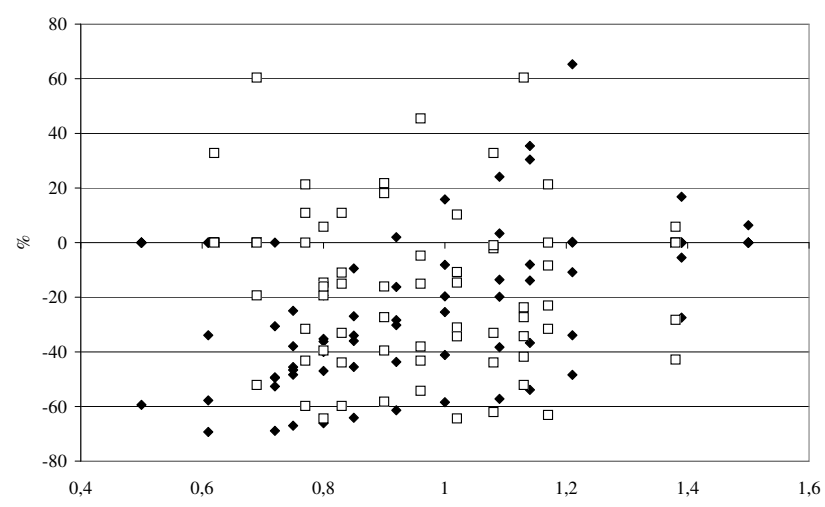

Fig. 11. Flood peak errors in percentages in function of $f$ (filled diamonds) and $f_{c}$ (blank squares) values.

permitting NWP ensembles in order to enlarge the size of the ensemble. Considering their cost, the size of such convection-permitting NWP ensembles should still be limited (around 10-20 members) in the foreseeable future.

The PERT-RAIN method addresses the first source of uncertainty in flash-flood hydrological forecasting, that is QPF uncertainties. Other hydrological uncertainties, such as those associated with the initial soil moisture content or with the hydrological modelling system itself, will also be examined in the future in order to sample the total uncertainty associated with Mediterranean flash-flood forecasting.

\section{Appendix A}

\section{Definition of the three components of SAL (Wernli et al., 2008)}

SAL is an object-based quality measure, which evaluates three components concerning the structure of the precipitation field $(S)$, its amplitude $(A)$ and its location $(L)$. This measure is valid for a given geographical domain $\mathcal{D}$. It is based on the differences between a simulated precipitation field $R_{\text {mod }}$ and the observed field $R_{\mathrm{obs}}$.

The $A$ component is the normalised difference of the domain-averaged precipitation values:

$A=2 \cdot \frac{\overline{R_{\mathrm{mod}}}-\overline{R_{\mathrm{obs}}}}{\overline{R_{\mathrm{mod}}}+\overline{R_{\mathrm{obs}}}}$

It is a relative measure of the bias of the model over the domain $\mathcal{D}$. Values of the A component are between -2 and +2 and a perfect forecast corresponds to $A=0$.

Evaluation of $S$ and $L$ requires the identification of coherent precipitation objects in both forecast and observation.

The location component $L$ is the sum of two contributions denoted $L 1$ and $L 2$. $L 1$ is the normalised distance between the barycentre of the simulated field $\left(\mathbf{x}\left(R_{\bmod }\right)\right)$ and that of the observed field $\left(\mathbf{x}\left(R_{\text {obs }}\right)\right)$ over the whole domain $\mathcal{D}$.

$L 1=\frac{\left|\mathbf{x}\left(R_{\mathrm{mod}}\right)-\mathbf{x}\left(R_{\mathrm{obs}}\right)\right|}{d}$

with $d$ the maximum distance possible between two points of the domain $\mathcal{D}$. L2 takes into account the mean distance between the barycentre of the whole precipitation field $(\mathbf{x})$ and the barycentre of each individual object $\left(\mathbf{x}_{n}\right)$ This function is denoted $r$ :

$r=\frac{\sum_{n=1}^{M} R_{n}\left|\mathbf{x}-\mathbf{x}_{n}\right|}{\sum_{n=1}^{M} R_{n}}$

where $M$ is the total number of individual objects in the field, and $R_{n}$ is the integrated amount of precipitation for the object n. $L 2$ is then given by:

$L 2=2 \frac{\left|r_{\text {mod }}-r_{\text {obs }}\right|}{d}$

$L(=L 1+L 2)$ allows the global shift of the simulated field to be evaluated with respect to the observation. It also gives information about the spatial precipitation distribution. Values of the L-component are between 0 and +2 and a perfect forecast corresponds to $L=0$.

The structure component $S$ is based on the "scaled volume" of each precipitation object $V_{n}$ :

$V_{n}=\frac{R_{n}}{R_{n}^{\max }}$

where $R_{n}^{\max }$ is the maximum rainfall value within the object $n$. 
For the whole field, one can compute the weighted mean precipitation volume of all objects denoted $V$ :

$V=\frac{\sum_{n=1}^{M} R_{n} \cdot V_{n}}{\sum_{n=1}^{M} R_{n}}$

$S$ is then the normalised difference between observed and simulated $V$ :

$S=2 \cdot \frac{V_{\mathrm{mod}}-V_{\mathrm{obs}}}{V_{\mathrm{mod}}+V_{\mathrm{obs}}}$

Values of the $S$ component are between -2 and +2 and a perfect forecast corresponds to $S=0$. Positive values of $S$ correspond to simulated objects that are too-large compared to the observed ones or to a widespread simulated precipitation field when the observed field presents small convective events, i.e. the simulated objects are too flat. Conversely, negative values of $S$ correspond to too-small or too-peaked simulated objects.

\section{Appendix B}

\section{Statistical tools}

The skill of ensemble predictions (rainfall and streamflows) is evaluated in the study through the root mean square error (RMSE), the spread $(\sigma)$ and the ranked probability skill score. The RMSE is defined as:

$\mathrm{RMSE}=\sqrt{\frac{1}{N} \sum_{i=1}^{N}\left(m_{i}-o_{i}\right)^{2}}$

where $N$ is the total number of time steps, $o_{i}$ the reference value at time step $i$ and $m_{i}$ the mean of the forecast members.

The spread is computed as:

$\sigma=\frac{1}{N} \sum_{i=1}^{N} \sqrt{\frac{1}{n} \sum_{k=1}^{n}\left(x_{k, i}-m_{i}\right)^{2}}$

where $n$ is the number of forecast members and $x_{k, i}$ the value of member $k$ at time step $i$.

The Ranked Probability Score (RPS) derives from the Brier Score (BS) (Brier, 1950; Wilks, 1995). It considers the exceedance of K-1 thresholds. The forecasts are divided into $\mathrm{K}$ classes.

RPS $=\frac{1}{K-1} \sum_{k=1}^{K}\left[Y_{k}-O_{k}\right]^{2}$

where $Y_{k}$ and $O_{k}$ are the cumulated k threshold distributions for forecasts and observations respectively. RPS varies between 0 and $+\infty ; 0$ is for a perfect forecast. Then the Ranked Probability Skill Score (RPSS) situates the forecasted ensemble with respect to a reference forecast:

$\mathrm{RPSS}=1-\frac{\mathrm{RPS}}{\mathrm{RPS}_{\mathrm{ref}}}$
RPSS varies between $-\infty$ and $1 ; 1$ corresponds to a perfect forecast.

Acknowledgements. This work was carried out in the framework of the MEDUP project (Grant ANR-07-VULN-06-001), funded by the Vulnérabilité Milieux et Climat (VMC) programme of the National Research Agency (ANR).

Edited by: G. Molinie

Reviewed by: M.-H. Ramos and two other anonymous referees

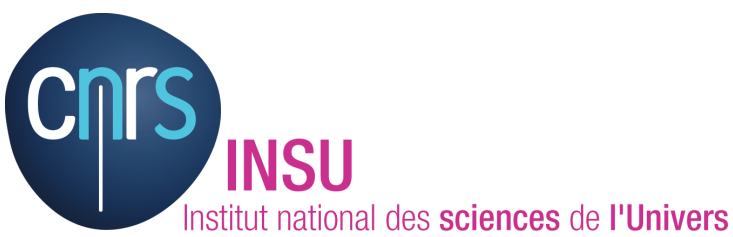

The publication of this article is financed by CNRS-INSU.

\section{References}

Anquetin, S., Yates, E., Ducrocq, V., Samouillan, S., Chancibault, K., Davolio, S., Accadia, C., Casaioli, M., Mariani, S., Ficca, G., Gozzini, B., Pasi, F., Pasqui, M., Garcia, A., Martorell, M., Romero, R., and Chessa, P.: The 8 and 9 September 2002 flash flood event in France: a model intercomparison, Nat. Hazards Earth Syst. Sci., 5, 741-754, doi:10.5194/nhess-5-741-2005, 2005.

Bartholmes and Todini: Coupling meteorological and hydrological models for flood forecasting, Hydrol. Earth Syst. Sci., 9, 333346, doi:10.5194/hess-9-333-2005, 2005.

Beaulant, A.-L., Joly, B., Nuissier, O., Somot, S., Ducrocq, V., Joly, A., Sevault, F., Déqué, M., and Ricard, D.: Statistico-dynamical downscaling for Mediterranean heavy precipitation, Q. J. Roy. Meteorol. Soc., 137 (656), 736-748, doi:10.1002/qj.796, 2011.

Bernard, P.: Aladin/AROME dynamical core, status and possible extension to IFS, in: ECMWF Seminar Proceedings, September 2004, http://www.ecmwf.int/publications/ libraryinNOV.2004, 2004.

Beven, K. and Kirkby, M. J.: A physically based, variable contributing area model of basin hydrology, Hydrol. Sci. Bull., 24, 43-69, 1979.

Beven, K. and Freer, J.: Equifinality, data assimilation, and uncertainty estimation in mechanistic modelling of complex environmental systems using the GLUE methodology, J. Hydrol., 249, 11-29, 2001.

Bouilloud, L., Chancibault, K., Vincendon, B., Ducrocq, V., Habets, F., Saulnier, G. M., Anquetin, S., Martin, E., and Noilhan, J.: An advanced coupling between the ISBA land surface model and the TOPMODEL hydrological model to simulate Mediterranean flash-floods, J. Hydrometeor., 11(2), 315-333, 2010.

Brier, G. W.: Verification of forecasts expressed in terms of probability, Mon. Weather. Rev., 78, 1-3, 1950.

Bowler, N., Pierce, C., and Seed, A.: STEPS: A probabilistic precipitation forecasting scheme which merges an extrapolation nowcast with downscaled NWP, Q. J. Roy. Meteorol. Soc., 132, 99, 132, 2127-2155, 2006.

Bubnovà, R., Hello, G., Bernard, P., and Geleyn, J. F.: Integration of the fully elastic equations cast in the hydrostatic 
pressure terrain-following coordinate in the framework of ARPEGE/ALADIN NWP system, Mon. Weather. Rev., 123, 515-535, 1995.

Caniaux, G., Redelsperger, J. L., and Lafore J. P.: A numerical study of the stratiform region of e fast-moving squall line. Part I. General description and water and heat budgets, J. Atmos. Sci., 51, 2046-2074, 1994.

Chancibault, K., Anquetin, S., Ducrocq, V., and Saulnier, G.-M.: Hydrological evaluation of high resolution precipitation forecasts of the Gard flash-flood event (8-9 September 2002), Q. J. Roy. Meteor. Soc., 132, 1091-1117, 2006.

Cloke, H.-L. and Pappenberger, F.: Ensemble flood forecasting: a review, J. Hydrol., 375(3-4), 613-626, 2009.

Courtier, P., Freydier, C., Geleyn, J.-F., Rabier, F., and Rochas, M.: The ARPEGE project at Météo-France, in: Workshop on numerical methods in atmospheric models, Reading, UK, ECMWF, 2, 193-231, 1991.

Davolio, S., Miglietta, M. M., Diomede, T., Marsigli, C., Morgillo, A., and Moscatello, A.: A meteo-hydrological prediction system based on a multi-model approach for precipitation forecasting, Nat. Hazards Earth Syst. Sci., 8, 143-159, doi:10.5194/nhess-8143-2008, 2008.

Deidda, R.: Rainfall downscaling in a space multifractal framework, Water Res. Res., 36, 1779-1794, 2000.

Diomede, T., Marsigli, C., Nerozzi, F., Paccagnella, T., and Montani, A.: Quantifying the discharge forecast uncertainty by different approaches to probabilistic quantitive precipitation forecast, Adv. Geosci., 7, 189-191, 2006, http://www.adv-geosci.net/7/189/2006/.

Diomede, T., Marsigli, C., Nerozzi, F., Papetti, P., and Paccagnella, T.: Coupling high-resolution precipitation forecasts and discharge predictions to evaluate the impact of spatial uncertainty in numerical weather prediction model outputs, Meteor. Atmos. Phys., 102, 1-2, 37-62, 2008.

Ducrocq V., Nuissier, O., Ricard, D., Lebeaupin, C., and Thouvenin, T.: A numerical study of three catastrophic precipitating events over southern France. II: Mesoscale triggering and stationarity factors, Quart. J. Roy. Meteor. Soc., 134, 131-145, doi:10.1002/qj.199, 2008.

Ferraris, L., Rudari, R., and Siccardi, F.: The uncertainty in the prediction of flash-floods in the northern Mediterranean environment, J. Hydrometeor., 3, 714-726, 2002.

Habets, F., Boone, A., Champeaux, J. L., Etchevers, P., Franchisteguy, L., Leblois, E., Ledoux, E., Le Moigne, P., Martin, E., Morel, S., Noilhan, J., Quintana-Segui, P., Rousset-Regimbeau, F., and Viennot, P.: The SAFRAN-ISBA-MODCOU hydrometeorological model applied over France, J. Geophys. Res., 113, D06113, doi:10.1029/2007JD008548, 2008.

Hamill, T. M., Hagedorn, R., and Whitaker, J. S.: Probabilistic forecast calibration using ECMWF and GFS ensemble forecasts. Part II: Precipitation, Mon. Weather Rev., 136, 7, 2620-2632, 2007.

Jasper, K., Gurtz, J., and Lang, H.: Advanced flood forecasting in Alpine watersheds by coupling meteorological observations and forecasts with a distributed hydrological model, J. Hydrol., 267, 40-52, 2002.

Komma, J., Reszler, C., Blöschl, G., and Haiden, T.: Ensemble prediction of floods - catchment non-linearity and forecast probabilities, Nat. Hazards Earth Syst. Sci., 7, 431-444, doi:10.5194/nhess-7-431-2007, 2007.
Krzysztofowicz, R.: Bayesian system for probabilistic river stage forecasting, J. Hydrol., 268, 16-40, 2002.

Lafore, J. P., Stein, J., Asencio, N., Bougeault, P., Ducrocq, V., Duron, J., Fischer, C., Hreil, P., Mascart, P., Masson, V., Pinty, J. P., Redelsperger, J. L., Richard, E., and Vilà-Guerau de Arellano, J.: The Meso-NH Atmospheric Simulation System. Part I: adiabatic formulation and control simulations, Ann. Geophys., 16, 90-109, doi:10.1007/s00585-997-0090-6, 1998.

Le Lay, M. and Saulnier, G. M.: Exploring the signature of spatial variabilities in flash flood events: Case of the 8-9 September 2002 Cévennes-vivarais catastrophic event, Geophys. Res. Lett., 34, L13401, doi:10.1029/2007GL029746, 2007.

Llasat, M. C.: Chapter 18: Storms and floods, in: The Physical Geography of the Mediterranean basin, edited by: J. Woodward, Published by Oxford University Press, 504-531, 2009.

Ludwig, R., Taschner, S., and Mauser, W.: Modelling floods in the Ammer catchment: limitations and challenges with a coupled meteo-hydrological model approach, Hydrol. Earth Syst. Sci., 7, 833-847, doi:10.5194/hess-7-833-2003, 2003.

Marsigli, C., Boccanera, F., Montani, A., and Paccagnella, T.: The COSMO-LEPS mesoscale ensemble system: validation of the methodology and verification, Nonlin. Processes Geophys., 12, 527-536, doi:10.5194/npg-12-527-2005, 2005.

Melone, F., Barbetta, S., Diomede, T., Perucacci, S., Rossi, M., Tessarollo, A., and Verdecchia, M.: Review and selection of hydrological models - Integration of hydrological models and meteorological inputs, Resulting from Work Package 1, Action 13, RISK AWARE - INTERREG III B - CADSES, 34 pp., http://www.smr.arpa.emr.it/riskaware/get.php?file= ReportWP1.13.pdf, 2005.

Molteni, F., Buizza, R., Palmer, T. N., and Petroliagis, T.: The ECMWF Ensemble Prediction System: Methodology and Validation, Q. J. Roy. Meteor. Soc., 122, 73-119, 1996.

Montanari, A.: Large sample behaviours of the generalized likelihood uncertainty estimation (GLUE) in assessing the uncertainty of rainfall-runoff simulations, Water Resour. Res., 41, W08406, doi:10.1029/2004WR003826, 2005.

Nicolau, J.: Short-range ensemble forecasting. WMO/CSB Technical Conference meeting, Cairns (Australia), December 2002 (Proceedings), 2002.

Noilhan, J. and Planton, S.: A simple parametrization of land surface processes for meteorological models, Mon. Weather. Rev., 117, 536-549, 1989.

Pellarin, T., Delrieu, G., Saulnier, G. M., Andrieu, H., Vignal, B., and Creutin, J. D.: Hydrological visibility of weather radars operating in mountainous regions: case study for the Ardèche catchment, France, J. Hydrometeor., 3, 5, 539-555, 2002.

Randrianasolo, A., Ramos, M. H., Thirel, G., Andrassian, V., and Martin, E.: Comparing the scores of hydrological ensemble forecasts issued by two different hydrological models, Atmos. Sci. Lett., 11, 2, 100-107, 2010.

Regimbeau, F. R., Habets, F., Martin, E., and Noilhan, J.: Ensemble streamflow forecasts over France, ECMWF Newsletter, 111, 2127, 2007.

Richardson, D.: Measures of skill and value of ensemble prediction systems, their interrelationship and the effect of ensemble size, Quart. J. Roy. Meteor. Soc., 127, 2473-2489, 2001.

Roberts, N. M., Cole, S. J., Forbes, R. M., Moore, R. J., and Boswell, D.: Use of high-resolution NWP rainfall and river flow 
forecasts for advance warning of the Carlisle flood, north-west England, Meteorol. App., 16(1), 23-44, doi:10.1002/met.94, 2009.

Rotach, M. W., Ambrosetti, P., Ament, F., Appenzeller, C., Arpagaus, M., Bauer, H.-S., Behrendt, A., Bouttier, F., Buzzi, A., Corazza, M., Davolio, S., Denhard, M., Dorninger, M., Fontannaz, L., Frick, J., Fundel, F., Germann, U., Gorgas, T., Hegg, C., Hering, A., Keil, C.,. Liniger, M., Marsigli, C., McTaggartCowan, R., Montaini, A., Mylne, K., Ranzi, R., Richard, E., Rossa, A., Santos-Muoz, D., Schr, C., Seity, Y., Staudinger, M., Stoll, M., Volkert, H., Walser, A., Wang, Y., Werhahn, J., Wulfmeyer, V., and Zappa, M.: MAP D-PHASE: Real-time Demonstration of Weather Forecast Quality in the Alpine Region, B. Am. Meteor. Soc., doi:10.1175/2009BAMS2776.1, 90, 1321-1336, 2009.

Schaake, J. C., Hamill, T. M., Buizza, R., and Clark, M.: HEPEX: the Hydrometeorological Ensemble Prediction EXperiment, J. Hydrometeor., 88, 1541-1547, 2007.

Seity, Y., Brousseau, P., Malardel, S., Hello, G., Bernard, P., Bouttier, F., Lac C., and Masson, V.: The AROME-France convective scale operational model, Mon. Weather. Rev., 139(3), 976-991, 2010.

Siccardi, F., Boni, G., Ferraris, L., and Rudari, R.: A Hydrometeorological approach for probabilistic flood forecast, J. Geophys. Res., 110, D05101, doi:10.1029/2004JD005314, 2005.

Tabary, P.: The new French radar rainfall product. Part I : methodology, Weather Forecast., 22, 3, 393-408, 2007.

Tabary, P., Desplats, J., Do Khac, K., Eideliman, F., Gueguen, C., and Heinrich, J.-C.: The new French radar rainfall product. Part II : Validation, Wea. Forecast., 22, 3, 409-427, 2007.

Theis, S. E., Hense, A., and Damrath, U.: Probabilistic precipitation forecasts from a deterministic model: a pragmatic approach, Meteorol. Appl., 12, 257-268, 2005.

Thielen, J., Schaake, J., Hartman, R., and Buizza, R.: Aims, challenges and progress of the Hydrological Ensemble Prediction EXperiment (HEPEX) following the third HEPEX workshop held in Stresa 27 to 29 June 2007, Atmos. Sci. Lett., 9, 29-35, 2008.

Thielen, J., Bartholmes, J., Ramos, M.-H., and de Roo, A.: The European Flood Alert System - Part 1: Concept and development, Hydrol. Earth Syst. Sci., 13, 125-140, doi:10.5194/hess-13-1252009, 2009.

Thirel, G., Rousset-Regimbeau, F., Martin, E., and Habets, F.: On the impact of short-range meteorological forecasts for ensemble stream flow predictions, J. Hydrometeorol., 9, 6, 1301-1317, 2008.
Thirel, G., Regimbeau, F., Martin, E., Noilhan, J., and Habets, F.: Short-and medium-range hydrological ensemble forecasts over France, Atmos. Sci. Lett., 11, 2, 72-77, 2010.

Vié, B., Nuissier, O., and Ducrocq, V.: Cloud-resolving ensemble simulations of heavy precipitating events: uncertainty on initial conditions and lateral boundary conditions, Mon. Weather. Rev., 139, 403-423, doi:10.1175/2010MWR3487.1, 2010.

Vincendon, B., Ducrocq, V., Dierer, S., Kotroni, V., Le Lay, M., Milelli, M., Quesney, A., Saulnier, G.-M., Rabuffetti, D., Bouilloud, L., Chancibault, K., Anquetin, S., Lagouvardos, K., and Steiner, P.: Flash flood forecasting within the PREVIEW project: value of high-resolution hydrometeorological coupled forecast, Meteor. Atmos. Phys., 103, 115-125, 2009.

Vincendon, B., Ducrocq, V., Saulnier, G. M., Bouilloud, L., Chancibault, K., Habets, F., and Noilhan, J.: Benefit of coupling the ISBA land surface model with a TOPMODEL hydrological model dedicated to Mediterranean flash floods, J. Hydrol., 394, 256-266, doi:10.1016/j.jhydrol.2010.04.012, 2010.

Wernli, H., Paulat, M., Hagen, M., and Frei, C.: SAL-A novel quality measure for the verification of quantitative precipitation forecasts, 2008, Mon. Weather. Rev., 136, 4470-4487, 2008.

Wilby, R. L. and Wigley, T. M. L.: Downscaling general circulation model output: a review of methods and limitations, Prog. Phys. Geogr., 21, 530-548, 1997.

Wilks, D. S.: Statistical methods in the Atmospheric sciences: An introduction, Academic Press, 467 pp., 1995.

$\mathrm{Xu}, \mathrm{C}$.: From GCMs to river flow: a review of downscaling methods and hydrologic modelling approaches, Prog. Phys. Geogr., 23(2), 229-249, 1999.

Xuan, Y., Cluckie, I. D., and Wang, Y.: Uncertainty analysis of hydrological ensemble forecasts in a distributed model utilising short-range rainfall prediction, Hydrol. Earth Syst. Sci., 13, 293303, doi:10.5194/hess-13-293-2009, 2009.

Zappa, M., Beven, K., Bruen, M., Cofio, A., Kok, K., Martin, E., Nurmi, P, Orfila, B., Roulin, E., Schrater, K, Seed, A, Szturc, J., Vehvilinen, B., Germann, U., and Rossa, A.: Propagation of uncertainty from observing systems and NWP into hydrological models: COST-731 Working Group 2, Atmos. Sci. Lett., 11(2), 83-91, 2010.

Zehe, E., Becker, R., Bardossy, A., and Plate, E.: Uncertainty of simulated catchment runoff response in the presence of threshold processes: Role of initial soil moisture and precipitation, J. Hydrol., 315, 183-202, 2005. 